\title{
Representation and Phenomenalism in the Critique of Pure Reason
}

\author{
Rafael Graebin Vogelmann \\ rafael.vog@gmail.com \\ (Universidade Federal do Rio Grande do Sul, Rio Grande do Sul, Brasil)
}

\begin{abstract}
Kant has often been accused of being a phenomenalist, i.e., of reducing spatial objects to representations that exist only in our minds. I argue against this reading. Given Kant's claim that appearances are mere representations, the only way to avoid the accusation of phenomenalism is to provide an alternative conception of "representation" according to which the claim that something is a mere representation does not entail that it is a mere mental item (or an organized collection of mental items). I offer evidence that Kant does not conceive of representations as mental items and outline an alternative conception of representations.
\end{abstract}

Keywords: Representation; Phenomenalism; Spatial Objects; Mental Entities; Transcendental Idealism.

DOI: http://dx.doi.org/10.11606/issn.2318-9800.v24i1p151-172

\section{Introduction - Idealism, Representation and Phenomenalism}

In the Appendix to the Prolegomena, Kant expresses his profound dissatisfaction with the review of the Critique of Pure Reason that came to be known as the GarveFeder review. He claims he would completely ignore the review was it not for the fact that it provided an occasion for the correction of some gross misunderstandings regarding the Critique (Prol., 4:373). ${ }^{1}$ According to the review, Kant reduces the world and ourselves to representations that exist only in the mind and conceives of objects as collections of representations organized according to certain laws. It, therefore, clearly draw parallels between Kant's positions and Berkeley's idealism (according to which all there is are thinking beings and modifications of such beings). Kant's indignation, however, may seem surprising given the characterization of transcendental idealism as the doctrine that appearances are "mere representations" (KrV, A369) and the claims that matter is "valid only for appearance - which,

1 Quotations from the Prolegomena to Any Future Metaphysics (Prol.) are from Gary Hatfield's translation (New York: Cambridge University Press, 2004). Quotations from the Critique of Pure Reason (KrV) are from Paul Guyer's and Allen Wood's translation (Cambridge: Cambridge University Press, 1998). 
separated from our sensibility, is nothing", that external objects (bodies) are mere appearances and, therefore, only "a species of representations" and "nothing separated from them" (KrV, A370) and that the objects we comprehend through the representation of matter and corporeal things "are merely appearances, i.e., mere modes of representation, which are always found only in us, and their reality, just as much as that of my own thoughts, rests on immediate consciousness" (KrV, A372). In light of these claims, the accusation of phenomenalism, according to which Kant reduces every empirical object to mere mental entities, seems natural. Kant even claims that space and time and, with them, all appearances "are not things, but rather nothing but representations, and they cannot exist at all outside our mind" (KrV, A429/B520).

If we take into account the context in which the formulation of transcendental idealism above appears, the accusations put forward in the Garve-Feder review become yet more plausible. The passage in question is part of the discussion of the Fourth Paralogism of Pure Reason. Paralogisms are formal fallacies (KrV, A341) and Kant's goal in this section is to show that the skeptic argument for the conclusion that the existence of external objects is doubtful is a paralogism. The argument is the following: (i) that whose existence can be inferred only as a cause of given perceptions has only a doubtful existence; (ii) the existence of external objects is not immediately perceived but can only be inferred as the cause of given perceptions; (iii) therefore, the existence of external objects is doubtful (KrV, A366-7). Kant claims that the transcendental idealist, given his reduction of external objects to mere representations, can avoid this skeptical conclusion because he can "concede the existence of matter without going beyond mere self-consciousness and assuming something more than the certainty of representations in me, hence the cogito, ergo sum" ( $\mathrm{KrV}, \mathrm{A} 370)$. Kant is here dealing with the problem of the Cartesian skepticism and, it seems, he hopes to avoid the problem by reducing external objects to the condition of mental entities whose existence the skeptic admits to be indubitable - there is no need to infer the existence of external objects because these object are only a species of the mental states of which we are immediately conscious. And this is exactly the same answer Berkeley gives to the problem. ${ }^{2}$ Given the textual evidence, both the accusation of phenomenalism and the comparison with Berkeley are quite natural.

Unsurprisingly, therefore, a number of interpreters agree with the Garve-Feder review in presenting Kant as a phenomenalist. Kemp Smith in his classic commentary claims that Kant refutes the Cartesian skeptic by accepting Berkeley thesis that objects are nothing but ideas (Smith, 2003 [1918], p.304-5). Turbayne reads Kant in the same manner, claiming that for Kant external objects have the same ontological

2 On Berkeley's answer to the Cartesian skeptic, see Turbayne (1955, p.229-236). 
status Locke and Descartes attribute to ideas (Turbayne, 1955, p.234). Strawson writes that according to Kant the physical world "only seems to exist, [but] is really nothing apart from perceptions" (Strawson, 1966, p.238). Guyer claims that Kant "degrade ordinary objects to mere representations of themselves, or identify objects possessing spatial and temporal properties with mere mental entities" (Guyer, 1987, p.335). And he adds, commenting on the anti-skeptical strategy deployed in the Fourth Paralogism, that Kant holds that spatial objects need to "be reduced to what are ontologically merely states of the self, in order to render them safe from doubt" (Guyer, 1987, p.280-1). Finally, Van Cleve holds that according to Kant objects in space and time are "logical constructions out of perceivers and their states" and that this "makes Kant a phenomenalist" (Van Cleve, 1999, p.11).

The goal of this paper is to reject the phenomenalist interpretation of transcendental idealism. Kant's official answer to the Garve-Feder review appears in his Prolegomena. One would, therefore, expect this text to contain clues for a non-phenomenalist reading of Kant's position. In that text, however, Kant main concern is to distinguish his positions from Berkeley's and he does not address explicitly the accusation of phenomenalism. I shall argue in the next section that the considerations Kant appeals to in distinguishing his positions from Berkeley's are not sufficient to fend off the accusation of phenomenalism if they are not accompanied by a reconception of the notion of representation. If nothing else could be said in order to bring out what is original in Kant's transcendental idealism, then we would have to accept Frederick Beiser's diagnosis: that although there may be some differences between Kant's and Berkeley's systems, both advocate the central principle of modern idealism - that the objects of our awareness are nothing but ideas or representations (Beiser, 2002, p.103).

Given Kant's explicit commitment to the thesis that spatial objects are mere representations, the only way to fend off the accusation of phenomenalism is to provide an alternative conception of "representation" according to which the claim that something is a mere representation does not entail that it is a mere mental item (or an organized collection of mental items). In section 3, I argue that there is evidence that Kant does not conceive of representations as mental items. The remaining of the paper is dedicated to the development of a conception of representation that allows us to fend off the accusation of phenomenalism. I argue that the claim that appearances are representations must be taken as a claim about the limits of our knowledge: appearances are said to be representations because when we are in contact with them we are in contact with something under a mode of presentation that is ultimately attributable to the conditions of our experience. 


\section{Kant's Answer to the Garve-Feder Review}

If we conceive of representations as "mere ideas", "mere states of the self", "mental entities" or "states of the perceiver", then Kant's answer to the GarveFeder review in the Prolegomena does not succeed in fending off the accusation of phenomenalism.

(i) In Note II, Kant quotes a passage from the Garve-Feder review according to which his transcendental idealism reduces spatial objects to "mere representations in us, and exist nowhere else than merely in our thoughts" (Prol., 4:288). He then asks whether the claim that spatial objects are representations makes his position a variety of idealism (understood as the thesis that everything there is are thinking beings and their determinations) and appeals to the notion of things-in-themselves to offer a negative answer to that question:

I say in opposition [to idealism]: There are things given to us as objects of our senses existing outside us, yet we know nothing of them as they may be in themselves, but are acquainted only with their appearances, that is, with the representations that they produce in us because they affect our senses (Prol., 4:289).

It is noteworthy that Kant does not comment explicitly on the claims that the representations in question are "in us" and that they exist "merely in our thoughts". For that reason it is not clear whether $(a)$ he accepts that the reduction of spatial objects to mental entities is a consequence of his transcendental idealism and hopes to show that it nevertheless does not commit him to the claim that only thinking beings exist (I shall refer to this thesis as "material idealism") or (b) he hopes to show that the reduction of spatial objects to mental entities is not a consequence of transcendental idealism properly understood.

If $(\mathrm{a})$ is the case, then the accusation of phenomenalism is correct and Note II should be read as an attempt at showing that phenomenalism does not entail material idealism. This is the natural way to read the passage, for Kant claims that his positions are not a variety of material idealism because he acknowledges the existence of something unknown that affects our senses and thus produces representations in us. This answer, however, if we do not have a non-mentalist conception of representation, leaves the claim that Kant reduces spatial objects to mental entities unscathed, for these objects are identified with our representations and not with that which produces the representations.

If we hope to find an answer to the accusation of phenomenalism in this passage, we must read it as (b) an attempt at denying that phenomenalism is a consequence of transcendental idealism properly understood. However, given the claim that appearances are representations produced in us when we are affected by things in 
themselves, that would require a non-mentalist conception of representation and the passage we are considering points to no such conception. ${ }^{3}$ Indeed, the claim that representations are produced in us when our senses are affected by things-inthemselves strongly suggests a mentalist conception of representations. ${ }^{4}$

(ii) In Note III Kant defends himself from the accusation that transcendental idealism reduces the sensible world to sheer illusion and in the Appendix he claims that for Berkeley experience has no criteria of truth and that, for that reason, he reduces all experience to sheer illusion (Prol., 4:374-5). The point is clear: Kant is claiming that he can hold on to the distinction between reality and illusion whereas Berkeley cannot. Since the considerations put forward in the Appendix are Kant's official answer to the Garve-Feder review one would expect to find in those claims an answer to the accusation of phenomenalism but, again, if we hold on to a mentalist conception of "representation", then those considerations leave the accusation of unscathed.

According to Kant, the distinction between truth and dream (i.e., illusion) does not rest on the correspondence between representation and object (for spatial objects are mere representations) nor on the content of the representations, but rather on the way in which representations are connected according to rules (Prol. 4:290). The rules that provide the criteria of truth must, however, be universal and necessary and, therefore, a priori and only transcendental idealism can account for a priori laws. Berkeley, because he conceives of space as an empirical representation among others, cannot account for such laws and, therefore, has no criteria of truth by means of which to distinguish between truth and illusion (Prol., 4:375).

Now, suppose Kant has a good argument for the claim that a priori laws are necessary if we are to have a criterion of truth. If that were the case, it would allow us to see an important difference between Kant's transcendental idealism and Berkeley's material idealism. Nevertheless, without an alternative conception of representation, that would hardly amount to an answer to the accusation of phenomenalism. If we assume representations to be mental items, Kant's idealism would be reduced to the conjunction between phenomenalism and a rationalist criterion of truth. ${ }^{5}$ Again, the claim that Kant reduces everything to representation

3 To be sure, I do not hold that the quoted passage fails to provide an answer to the accusation of phenomenalism. My point is rather that it cannot do so if we hold on to a mentalist conception of representation and that no alternative conception of representation is suggested by Note II of the Prolegomena.

4 In order to avoid this suggestion, the claim that we are acquainted only with representations in us must be read in light of the distinction between the transcendental and the empirical sense of "in us". This distinction is discussed below. Once it is in place the claim that we are acquainted only with representations "in us" (in the transcendental sense) can be made compatible with the claim that these representations are not mental items "in us" (in an empirical sense).

5 On this topic I agree with Beiser (2002, p.103). 
and, in particular, objects to collections of representations arranged according to certain rules would remain unscathed.

Indeed, a number of commentators find in the claim that conformity to laws is the criteria to distinguish between truth and illusion a further reason to ascribe to Kant the phenomenalist thesis that objects in space and time are logical constructs from representations understood as mental items. Van Cleve (1999, p.11) and Beiser (2002, p.106) defend this thesis. According to Beiser, spatial objects are appearances but cannot be reduced to mere individual representations. Spatial objects are "distinct from their representations not in an ontological sense - they are not an entity that exists independent of them - but only in a formal sense - they are wholes of which individual perceptions or representations are only parts" (Beiser, 2002, p.120). This analysis of the notion of object is imposed, according to Beiser, by the fact that we cannot step out of realm of our representation to compare them to something existing independently of them: once we realize that we have to deal with nothing more than our own representations "it becomes necessary to account for the concept of the object within the realm of consciousness itself" and we do that by ascribing to objects the status of "synthesis of representations" (Beiser, 2002, p.135-6). This is clearly a phenomenalist reading of Kant - it accounts for the notion of object in terms of mental items, confined to the realm of consciousness, arranged according to certain rules for the unification of representations.

In defending Kant from the accusation of phenomenalism, Allison points to passages of the Critique of Pure Reason in which Kant makes claims about the reality or actuality of unperceived entities that very much resemble the claims in Note III of the Prolegomena (Allison, 2004, p.39-42). In these passages, Kant holds that an appearance is real or that something is actual, even if not actually perceived, as long as it is connected with some actual perception in accordance with the analogies of experience. According to Allison, what Kant means is that an entity is real or actual as long as there is a "lawful connection or "causal route" connecting it to an actual experience, that is, to a perceived appearance (Allison, 2004, p.40). Allison hopes this to be enough to distinguish Kant's transcendental idealism from Berkeley's material idealism, according to which an unperceived entity $x$ can be said to be real if a hypothetical of the form "if one were to find oneself in a particular position, had proper instruments, and so forth, then one would perceive $x$ " obtains. Surely there is a difference between these criteria of actuality, for Kant's criterion opens up space for the actuality of things that we could never perceive, not even if our sensory apparatus was vastly improved, whereas for Berkeley an actual object should be actually perceivable in some counterfactual situation. That by itself, however, is not enough to fend off the accusation of phenomenalism, for one could take Kant's position to be the mere conjunction of phenomenalism and a rationalist account 
of the truth-conditions of claims about unperceived objects (which focus on the lawful connection of the postulated object with actual experience rather than on hypothetical mental episodes in some consciousness). To be sure, Kant's criterion allows us to speak of real or actual objects that do not figure in anyone's experience and, to this extent, are not mental representations in anyone's mind. But the same can be said of the phenomenalist's hypothetical criterion - an object can be correctly said to be real and exist right now, even though it is not perceived by anyone and, therefore, is not a representation in anyone's mind, as long as it is true that if one were to find oneself in such-and-such counterfactual circumstances, one would perceive it. If we hold on to the idea that representations are mental entities, ${ }^{6}$ the fact that Kant's criterion of actuality for unperceived objects is spelled out in terms of a priori and empirical laws instead of claims about hypothetical perceptions may well point to a superficial difference between transcendental idealism and Berkeley's material idealism, but the fact remains that both systems share the central tenet of idealism - the claim that the objects we perceive and that furnish empirical reality are representations and, therefore, mental entities.

(iii) Finally, in the Appendix, Kant makes another effort to distinguish his position from Berkeley's. According to Kant, the thesis that characterizes Berkeley's idealism is the claim that "all cognition through the senses and experience is nothing but sheer illusion, and there is truth only in the ideas of pure understanding and reason"; in contrast, we are told, Kant holds that all cognition through pure understanding or pure reason is nothing but illusion and that truth can only be found in experience (Prol., 4:374). Leaving aside the question of how the thesis ascribed to Berkeley could be reconciled with his empiricism, it is far from clear how the ascription of these platonic leanings to Berkeley could provide an answer to the accusation of phenomenalism. Given Kant's strategy in answering the Cartesian skeptic in the Forth Paralogism, it seems that he can hold that experience gives us access to the truth only because he reduces the sensible world to mere representations conceived of as mental items.

I conclude, therefore, that, in the absence of a non-mentalist conception of representation, Kant's official answer to the Garve-Feder review is unsatisfactory for it actually fails to approach the accusation of phenomenalism. The only way to do away with that accusation is to provide an alternative conception of "representation" according to which representations are not mental items.

\footnotetext{
6 I do not claim that Allison holds a mentalist conception of representations. Quite the opposite, actually, as we shall see in section 4. My point is simply that considerations about Kant's criteria for the actuality of unperceived objects cannot provide an answer to the accusation of phenomenalism as long as we hold on to a mentalist conception of representation and that these same considerations do not suggest any alternative conception.
} 


\section{Evidence that Kant does not conceive of Representations as Mental Items}

If representations are mental items, there is no way to avoid the claim that transcendental idealism is a form of phenomenalism. There are good reasons, however, to suppose that Kant did not conceive of representations as entities that exist only in our minds (or, at least, that that cannot be his considered view). I shall present two considerations in favor of this thesis. Both are related to the distinction between appearances and things-in-themselves that lies at the very center of transcendental idealism. If the argument of this section is successful, it shows that the differences between transcendental idealism and material idealism are much deeper than Kant's claims in the passages of the Prolegomena consider above suggest. To comprehend this difference, however, we will need an alternative understanding of what representations are.

(A) We come to think of representations as mental items because we think of them as mental images corresponding to objects that are independent of them. Given Kant's insistence in the claim that appearances are representations, we are led to think of appearances in the same way, and then it is natural to take Kant to be a phenomenalist. Nevertheless, there is textual evidence that Kant does not conceive of appearances as items that could be separated and isolated from the things of which they are appearances. In several passages Kant claims that we can take one and the same object either as an appearance or as a thing-in-itself:

Since, however, in the relation of the given object to the subject, such properties depend upon the mode of intuition of the subject, this object as appearance is to be distinguished from itself as object in itself ( $\mathrm{KrV}, \mathrm{B} 69$, my emphasis).

[...] the distinction between things as objects of experience and the very same things as things in themselves, which our critique has made necessary [...] (KrV, Bxxvii, my emphasis).

In these passages Kant claims that an object qua appearance must be distinguished from itself qua thing-in-itself. This suggests that the distinction between appearance and things-in-themselves is not a distinction between two ontologically distinct items, but rather between two ways in which to consider an object. Appearance and thing-in-itself are aspects of the same unity. This suggestion is reinforced by the following passage:

[A]ppearance [...] always has two sides, one where the object is considered in itself (without regard to the way in which it is to be intuited, the constitution of which however must for that very reason always remain problematic), the other where the form of the intuition of this object is considered ( $\mathrm{KrV}, \mathrm{A38/B55)}$. 
Allison's two-aspect reading of the distinction between appearance and thingin-itself can easily account for these passages. According to Kant, for something to be an object for us, it has to conform itself to certain conditions, some of which are imposed by the forms of our sensible intuition. Allison holds that a thing-in-itself is just an object considered apart from these conditions, i.e., considered in abstraction from the conditions of our cognition (from this it follows trivially that we can have no knowledge of things-in-themselves, for they do not conform to the conditions of our cognition). In contrast, an appearance is the same thing considered as it presents itself to beings such as ourselves, i.e., as conforming to the conditions of our cognition (Allison, 2004, p.16-18). An appearance, therefore, is not something over and above the thing-in-itself, but only a way in which to consider something independent of us that takes into account our particular mode of intuition and cognition. This shows that appearances are not mental images of mind-independent things-in-themselves. If that was the case, appearances could, in principle, be thought of as something distinct and ontologically isolated from the things to which they correspond - and that would conflict with the suggestion that appearances and things-in-themselves are to sides of the same coin. ${ }^{7}$

The two-aspect reading is not, by itself, incompatible with the phenomenalist reading of transcendental idealism for one could argue in the following way: even if appearances cannot be isolated from the things-in-themselves, they can have properties that things-in-themselves cannot possess (for all we know, things-inthemselves may not be spatial, but Kant holds that spatial objects are appearances and, therefore, that at least some appearances have spatial properties); thus, even though appearances are not mental images that stand for things-in-themselves, Kant could have an independent argument for the thesis that every appearance is actually mental in nature (even though each appearance is only an aspect of something that is not mental in itself) and only to that extent a representation. There are good reasons, however, to believe that Kant does not hold this thesis. According to the passages quoted above, we think of an object as an appearance when we take into account the way in which it is intuited. The same is indicated by the claim that we

\footnotetext{
7 Kant's claim that things-in-themselves affect our senses and produce representations in us (as in Prol. 4:289) is naturally read as the claim that things-in-themselves affect us and thus produce in us mental representations (that conform to the forms of our intuition). This reading of the affection thesis is incompatible with the two-aspect reading for it takes appearances and things-inthemselves to be two separate objects, one of which is the cause of the other. In order to reconcile the affection thesis with the two-aspect reading we must take the former not as a metaphysical claim about how the mind is affected by a non-sensible entity but rather as a claim about how we should consider an object (namely, as a thing-in-itself) when we think of it as being given to us by intuition and thus subjecting itself to the forms of our sensibility. This is Allison's reading (see his 2004, p.64-73). Notice, however, that this reinterpretation of the affection thesis requires a nonmentalist conception of representation, for Kant claims not only that things-in-themselves affect us but that in doing so they produce representations in us. If representations are mental images, we cannot avoid the natural interpretation, which is incompatible with the two-aspect reading.
} 
call "certain objects, as appearances, beings of sense (phaenomena), because we distinguish the way in which we intuit them from their constitution in itself" (B306). The forms of our intuition are space and time. To hold, then, that every appearance is mental would involve holding that we never intuit an object according to the form of space. To argue in favor of this claim is to argue in favor of the thesis of illusionism (according to which spatial object merely seem to outside me) from which Kant is anxious to distance himself.

This provides good evidence that Kant does not conceive of appearances or representation as mental entities. We can go beyond this, however, and show that distinctions that are absolutely central to transcendental idealism render the claims that appearances are representation (to which Kant is clearly committed) and that representations are mental items incompatible.

(B) The claim that appearances or representations are mental entities entails that they are in us in some sense. Indeed, part of the textual evidence that leads to a phenomenalist reading of transcendental idealism is provided by Kant's claims that appearances are representation in us or found in us. In the discussion of the fourth paralogism, however, Kant draws a distinction between two senses of "outside us" (to which correspond two senses of "in us"): in the empirical sense, "things outside us" refers to external appearances (i.e., spatial objects); in the transcendental sense, "things outside us" refers to things as they are in themselves, independently of us and of our way of cognizing them (KrV, A373). Kant characterizes transcendental realism as the thesis that conflates these two senses, that is, the thesis that objects that are external in the empirical sense (spatial objects) are external in transcendental sense (i.e., are things-in-themselves, independent of us and of our sensibility). According to Kant, transcendental realism inevitably leads to Cartesian skepticism or "problematic idealism", according to which we cannot know for sure that spatial objects exist (KrV, A369). Kant, in contrast, favors transcendental idealism, according to which empirically external or spatial objects are transcendentally internal (that is, are "in us" in the transcendental sense) and, therefore, must be conceived of as "mere representations" (KrV, A369). Despite this reduction of spatial objects to the status of representations, we can still claim that these objects are outside us in the empirical sense because they are objects of the external sense, whose form is space. Spatial objects are really in space, but space itself is not independent of us.

With this distinction in mind, we can show that Kant's transcendental idealism leaves no room for the claim that representations are mental entities. Given that spatial objects are appearances and appearances are representations, if representations were mental items, then spatial objects should be "in us" in some sense. But Kant cannot claim that spatial objects are in us in the empirical sense and treating them as internal in the transcendental sense does not entails that they are 
mental items.

In the empirical sense of "in us", spatial objects clearly are not in us. Kant claims unequivocally that spatial objects are outside us in the empirical sense. Empirically external objects simply are "things that are to be encountered in space" (KrV, A373) and surely that is where we find spatial objects. These objects, whatever their ontological status as appearances turns out to be, are empirically external and, therefore, non-mental.

If spatial objects are supposed to be mental, then that should be a transcendental claim, but it is not at all clear what we could mean by saying that spatial objects are "mental" in a transcendental sense (and not only appearances or representations in a transcendental sense). According to transcendental idealism, spatial objects are transcendentally internal, but that means only that they should not be taken as things-in-themselves that are independent of the forms of our sensibility. This means that when we come into contact with spatial objects, we get no knowledge of how they are independently of our way of cognizing them. Now, according to our mode of cognizing them, spatial objects are indeed spatial and not mental. Therefore, the only way to make sense of the claim that spatial objects are "mental in a transcendental sense" is to take it as the claim that spatial objects are in themselves mental, that is, that they are mental independently of our way of cognizing them. But transcendental idealism frowns upon such incursions beyond the limits of our possible experience and, therefore, cannot include the claim that spatial objects are mental in this sense. Two further considerations reinforce this point.

(i) Kant explicitly claims that we do not know how that which is empirically material is in itself. We cannot even know whether the mental and the material, consider in themselves, are distinct:

[...] if we compare the thinking I not with matter but with the intelligible that grounds the outer appearance we call matter, than because we know nothing at all about the latter, we cannot say that the soul is inwardly distinguished from it in any way at all $(\mathrm{KrV}, \mathrm{A} 360)$.

At the empirical level we can clearly distinguish between the mental and the material - both are appearances, but they belong to different senses. If we try, however, to think about the transcendental ground of these appearances and ask ourselves whether they are distinct or the same, we are left with no answer. Things-in-themselves are things considered in abstraction from the conditions of our cognition. To declare them to be either material or mental is to purport to know something that does not satisfy the conditions of our cognition, and that is clearly impossible. We can only positively declare something to be mental at the empirical level and at this level spatial objects are not mental.

(ii) If we conceive of representations as mental entities, we must ascribe 
them to some mind. If empirical objects are not mental in the empirical sense, then they cannot be ascribed to empirical subjects as mental states. They could only be ascribed to the "thinking I" conceived of as a thing-in-itself. The passage that immediately precedes the last quoted passage may suggest that this is exactly how Kant conceives of matter:

[...] if by a "soul" I understand a thinking being in itself, then it is already in itself an unsuitable question to ask whether or not it is of the same species as matter (which is not a thing in itself at all, but only a species of representations in us); for it is already self-evident that a thing in itself is of another nature than the determinations that merely constitute its state (A360).

In this passage, Kant seems to claim that matter is a kind of representation and that representations are determinations of a thinking being conceived of as a thing-in-itself. The location of this passage in the section on the paralogisms of pure reason suggests, however, a different reading. The section on the paralogisms aims at criticizing the "rational doctrine of the soul" - a supposed a priori science of the thinking I or the soul. Among the claims that compose this doctrine we find the thesis that the thinking I is a substance, is simple and is a person. Kant aims at showing that the arguments that ground such claims are paralogisms, i.e., formal fallacies (KrV, A341). The quoted passage occurs in the discussion of the second paralogism, which was supposed to show that the thinking $I$ is a simple substance. In the context it occurs, Kant is attempting to show that thoughts should be ascribed not to the soul, consider as a kind of substance, but to human beings, i.e., an empirical being that qua external appearance is a body and qua internal appearance thinks ( KrV, A359360). The two passages quoted above just add that, even if we admit the hypothesis (that can only be thought and never known to be true) that the thinking $I$ is, in itself, a simple substance, the question whether the thinking being is material or not cannot be made, for is either has a self-evident answer or cannot be answered at all.

The section on the paralogisms aims at showing that we cannot have any knowledge about the thinking I conceived of as a thing-in-itself. This "I" is merely a formal condition of thought (the "I think" that must be able to accompany all my thoughts). According to Kant, the paralogisms are the expression of a transcendental illusion that derives from taking a subjective condition of our thought (namely, the formal role the representation of the thinking I has in unifying our consciousness) as a cognition of an object ( $\mathrm{KrV}, \mathrm{A396})$. When we describe the logical function played by the I in "I think" we are lead to believe we are acquiring knowledge about an object, when, in reality, we cannot know whether there is a soul, conceived of as a thingin-itself, that is a simple substance and whose determinations are representations.

Given this characterization of the aims of the section on the paralogism, Kant seems to be committed to the following claims: (i) spatial objects are representations; 
(ii) as affirmed in the discussion of the fourth paralogism, we can be certain of the existence of spatial objects; (iii) we cannot be certain of the existence of a thinking being in itself (with a mental life) to whom the representations spatial objects consist in could be ascribed to (as mental states); (iv) these representation also cannot be ascribed to the empirical I (of which we are aware by means of the inner sense) for at the empirical level mental states are such that they cannot be objects of the outer sense, as external objects plainly can. If we are sure of the existence of certain representations, but are not sure of the existence of any mind on which those representations could subsist as a mental state, then there must be a sense of "representation" on which representations are not mental items - and this must be the sense Kant is using when he claims that spatial objects are representations.

\section{An Alternative Conception of Representation}

If representations are not mental entities, what are they? According to Allison, when Kant claims that bodies are representations in us, he is not claiming that bodies are private mental entities; nevertheless, representations are referred to a "transcendental consciousness":

This transcendental consciousness, and its equivalent, transcendental apperception is not to be construed as either an individual or super-individual mind. Kant defines it quite simply as "the bare representation I" (A117 note) which constitutes the logical form of all knowledge. It is thus a logical principle, which much like a Platonic archetype, provides the form of unity to which every empirical, i.e. individual consciousness, must conform if it is to yield consciousness of a public, objective world. To say, therefore, with Kant that appearances are representations in the mind is not to make either a psychological or an ontological claim, but merely to point to the subjective sources of the a priori conditions to which every object of experience must conform. These subjective conditions (both sensible and intellectual) are not the ground of the being of objects of experience, but of their being known, and these objects of experience are called appearances because they can only be known in relation to these subjective conditions, and hence, not as they are in themselves. The claim is of a completely different order than Berkeley's contention that sensible things are "collections of ideas", understood in the Cartesian sense as contents of an individual consciousness (Allison, 1973, p.111).

I will come back to the idea of transcendental consciousness in what follows. For now, let us focus on another feature of Allison's proposal: according to him, Kant's claim that spatial objects are representations is a claim about the conditions to which every object of experience must conform. The claim is a familiar one. If we restrict our attention to the sensible conditions of experience, it goes like this: in order for objects to figure in our experience we must intuit them; space and time are the forms of intuition and for that reason we can only intuit objects that conform 
to these forms (we either intuit spatial objects in space and time or mental states in time only); in this sense, intuition in space and time is a condition of our cognition and, therefore, we can only know spatial and temporal objects. According to Allison, to say that spatial objects are representations is only to call attention to the fact that these conditions are derived from the nature of our cognition (that relies on sensible intuition with a particular form) rather than from a supposed insight into the nature of things themselves.

Luigi Caranti makes a similar point when he claims that the identification of objects with representations is natural given that the objects of experience are "always structured by the forms through which we are bound to represent things" and that to claim that they are representations is simply a way of saying that the "the objects of our experience are subject to the forms of our sensible representing" (Caranti, 2007, p.45-6). This, however, is of little help if not accompanied by an explanation of what it is for us to "represent things". If representing something is just to produce a mental image of the thing and what structures the objects of experience are simply the subjective conditions of this mental act, then these objects are nothing but mental entities - for the form of a mental act can structure only the act itself or its mental products. ${ }^{8}$ Instead of speaking of the forms through which we represent things, I suggest we think of the conditions imposed by the forms of intuition as condition for something to figure in our experience.

But that, one may worry, will simply displace the problem: what does it mean to say that an object figures in our experience in a way that does not necessarily correspond to the way it is in itself, if not that we come up with a mental image of the object to which we add some features it does not actually possess? The considerations of the previous section provide an answer to this question. The key to this answer is in the fact that thoughts, sensations, mental images and any other item that may be part of our mental life are themselves appearances that figure in our experience. ${ }^{9}$ We can only be aware of a mental image in time (as an item in a temporally ordained series of mental items presented to us). Temporality, however, is a form of sensible intuitions and not a feature of things as they are in themselves, independently of our way of experiencing them. That is, a mental image itself is something that figures in

8 The same can be said with regard to Allison's claim that the "central tenet of transcendental idealism" is the claim that "objects must conform to the conditions under which we can alone represent them to ourselves as objects" (2004, p.37). Without a non-mentalist conception of representation, we cannot but conceive of the act of representing something as the production of a mental image of the thing in question and then we cannot avoid the phenomenalist reading.

$9 \mathrm{I}$, therefore, agree with Allison (2004, p.38) in that I hold that a fundamental difference between Kant's transcendental idealism and phenomenalist positions, such as Berkeley's, is that the later regard mental entities as things-in-themselves while the former claims that mental entities are appearances. That answer to the accusation of phenomenalism will not be complete, however, without a non-mentalist conception of representation in light of which we could offer a nonphenomenalist reading of transcendental idealism. 
our experience in a way that does not necessarily correspond to the way it is in itself. If we adopt a phenomenalist reading of "figures in experience" (according to which for an object to figure in our experience is for us to have a mental representation of it), we would be forced to claim that we produce mental images of mental images and then we would have an infinite regress in our hands. There must be, therefore, a sense in which appearances "figure in experience" that cannot be reduced to a form of mental representationalism. Mental entities figure in our experience in this primitive sense. And what is to stop us from saying that spatial objects figure in experience in the exact same sense? Someone could, it is true, present a skeptic argument to the effect that the only objects with which we have direct contact are mental objects. That argument would probably have the form of a traditional skeptic argument: the skeptic points to cases of illusory spatial experience, she claims that in such cases we cannot be in direct contact with a spatial object but only with something mental and then generalizes that to every possible experience - we have direct contact only with mental items. Kant, however, hopes to show that the idea that experience is restricted to mental items cannot be accepted - that is the aim of the Refutation of Idealism and Kant's position is already indicated in the first edition by the claims in the discussion of the fourth paralogism according to which without genuine external perceptions not even fictions and dreams are possible (KrV, A377). ${ }^{10}$ According to Kant, therefore, external appearances can figure in experience in exactly the same primitive sense in which mental states and entities do.

To have an experience in this sense is just to be in direct contact with an object (spatial or mental). Allais calls attention to the fact that the term "Vorstellungen", usually translated as "representation", could just as well be translated as "presentation" (Allais, 2015, p.13). That allow us to read the claim that bodies are representations in the following way: these appearances are said to be representations because when we are in direct contact with them we are presented to something that is independent of us (with a way of being that is independent of the conditions of our experience) but according to a way of appearing that is attributable to the conditions of our experience. ${ }^{11}$ If we consider a mental image,

10 Given that Kant clearly wishes to avoid skepticism and that our goal is merely to understand his conception of representation, we need not occupy ourselves here with his answer to these skeptical arguments.

11 There are many similarities between Allais' proposal and mine. We agree in rejecting a phenomenalist reading of transcendental idealism, in holding that appearances or representation are not mental items, that they are presented for subjects rather than represented by them and that, according to Kant, for a subject to perceive an object is just for a particular relation to hold between the subject and the object and, thus, that perception does not consist in the production of a mental image that corresponds to the object (a topic I discuss in the next section). Allais' conception of representation diverges from the one presented here mainly in that she holds that representations are mind-dependent and that this claim must be understood as a metaphysical claim (see, for instance, Allais, 2015, p.9, 36 and 57). Allais hold that, for Kant, spatial and temporal qualities are "essentially manifest qualities", i.e., qualities the object has only when presented to us and 
such as, for instance, the image (if there is such a thing) that memory provides when we remember the face of a loved one, we may characterize it as a "representation" in two senses: (i) in the sense that it is an image that stands for something else and (ii) in the sense that it is a thing that figures in our experience in a way (namely, temporally) that is not attributable to the way it is independently of figuring in our experience. Spatial objects are representations only in the second sense.

To claim that space and time are forms of our sensibility is not, therefore, to claim that they are forms imposed by our mind upon mental states that are produced in us by things - rather it is to claim that they are the forms that structure the sensible world (both spatial and mental) to the extent that it is accessible to us. But one may protest: if space and time are neither things-in-themselves nor features of things-inthemselves, then they must be a creation of the mind that perceives objects in space and time; and then, if space and time are mental inventions, everything that is to be found in space and time must likewise be a mental item.

Now, if a mind somehow produces space and time, it cannot be the mind of empirical subjects. People are beings that belong in the empirical world. They are curious creatures in that they can be taken both as external appearances (i.e., a body) and as internal appearances (i.e., a thinking being) (KrV, A359-360). However, people cannot be credited with casting empirical reality in the forms of space and time regardless of what aspect of them we focus on. On the one hand, understood as bodies, people are spatial objects among other spatial objects and can only affect them physically. On the other hand, if we take people to be empirical thinking beings, i.e., an internal appearance, then spatial objects are independent of them. To claim otherwise would be to reduce spatial objects to empirical mental entities or logical constructions from empirical mental entities - and that would amount to the acceptance of empirical idealism (which Kant rejects). Even if people, conceived of as thinking beings, can impose some form upon their thoughts or other mental states, they cannot impose a form upon spatial objects.

Therefore, if there is a mind that shapes empirical reality, it must be the mind

that cannot be ascribed to objects independently of their mode of appearing to us (Allais, 2015, p.117). She takes this claim to have metaphysical consequences, namely, that spatial and temporal qualities are mind-depend. If that were a metaphysical truth, we should be able to specify the mind on which these qualities depend, but, as I argue in what follows, we cannot do that in the framework of transcendental idealism. The claim that objects have spatial and temporal qualities that do not correspond to the way they are abstraction made of the conditions for them to figure in our experience (and are, in this sense, mind-dependent) should not be taken, therefore, as a metaphysical claim but rather as a transcendental claim (in the sense discussed in what follows) that purports only to draw the limits of experience and cognition. Discussing the details of Allais argument, however, is beyond the scope of this paper. We should rest content with the observation that Allais does not dispute the central claim of this section: that, for Kant, to claim that empirical objects are representations is to claim that they figure in our experience (are presented to us or appear to us) in a way that does not correspond to the way they are abstraction made from the conditions for them to figure in our experience. 
of a transcendental subject (and here we come back to the topic of transcendental consciousness). If, however, we think of the transcendental subject as the transcendental counterpart of the empirical thinking being, we go beyond the limits of our knowledge. That would amount to the thesis that we can, independently of experience, have knowledge of the existence of a thinking being, conceived of as a thing-in-itself, with a mental life characterized by a sensibility whose forms are space and time - exactly the kind of knowledge that was declared illusory in the section on the paralogisms. But if the mind that is supposed to shape empirical reality cannot be ascribed to empirical subjects nor to their noumenical counterparts (which are merely postulated), then space and time cannot be literally understood as the contribution of a thinking being to a reality that is not in itself spatial and temporal.

What, then, does it mean to say that space and time are forms of our sensibility? To understand this claim we must comprehend the idea of a transcendental subject in a different way. One option is to hold, following Allison, that in describing the consciousness of the transcendental subject (as when we say that from a transcendental point of view space and time are mere forms of the sensibility) we do not aim at describing an actual consciousness (and, thus, make no metaphysical claim). Rather, the purpose of this description is to draw the limits of the possible experience and knowledge. To claim that space and time are forms of the transcendental subject's sensibility, then, is just to claim that spatiality and temporality are conditions for something to figure in experience and, therefore, that our sensible experience is limited to spatial and temporal object.

We can understand the role of the notion of transcendental subject in Kant's philosophy in the following way: the conception of cognition we get if we conceive of the transcendental subject as a consciousness confronted with things-in-themselves is exactly the model of cognition put forward by transcendental realism - a consciousness is affected by things as they are independently of the conditions of its experience. This consciousness' mode of cognition consists in producing mental representations of things hoping that these representations correspond to the way things are in themselves. It may be possible to show that, in order to be able to produce these representations, the transcendental subject's consciousness must conform to certain conditions. For instance, it may be possible to show that in order to represent an object as something distinct from itself this consciousness must represent it on space and, therefore, that the representation of space must be available prior to the representation of any object (this is a possible interpretation of Kant's first argument for the claim that space is an a priori representation in the Transcendental Aesthetic). ${ }^{12}$ And it may be possible to thus establish that space is the form of the 
sensibility of one such consciousness. In this way we introduce a restriction on the kind of representation this consciousness can produce that is not imposed by the way things are in themselves. From the point of view of the transcendental subject, the features of representations that derive from these restrictions (such as the spatiality and temporality of objects) can be said to be merely ideal - they are an original contribution of his mind. And if space and time are ideal, then spatial and temporal objects and states should not be taken as things-in-themselves, independent of the transcendental subject. Rather, they are appearances, and, from the transcendental point of view, appearances are mere representations that exist only in the mind of the transcendental subject. We should, however, keep in mind that the description of the transcendental subject is a mere logical description of the conditions of experience and knowledge for a cognizing consciousness confronted with things that are independent of it. This description, by itself, provides no knowledge; particularly, the fact that this description is available does not show there to be a transcendental subject nor does it allow us to identify with this subject. The transcendental subject is a thing-in-itself and, as such, cannot be the object of a cognition. For all we know, we (i.e., people, bodily beings that belong in a world populated by other spatial and temporal objects) may be the only thinking beings there are - and we are not in the business of representing the spatial objects we are confronted with; they simply figure in our experience (in the sense explained above). That does not mean, however, that the description of the transcendental subject is useless. Quite the contrary: the description of the conditions of (mental) representability for a transcendental subject corresponds to a description of the conditions of experience for empirical subjects. For instance, if the transcendental subject can represent an object as distinct from himself only by representing it on space, then an empirical subject can experience an object as distinct from himself only by encountering it on space. The image of a transcendental subject that attempts to cognize things-inthemselves by means of representations serves, therefore, Kant's purpose of drawing the limits of possible experience and, consequently, knowledge (even if we come to discover that, as empirical subjects, our immediate experience is not, as the experience of the transcendental subject, limited to mental representations).

This allows us to understand why Kant claims that, from a transcendental point of view, space and time are mere forms of sensibility or that spatial objects are mere representations while at the same time claiming that his idealism concerns only the conditions of knowledge. The claim that, from a transcendental point of view, space and time are forms of sensibility can be read as the claim that spatiality and temporarily are conditions for things to figure in experience. And the claim that appearances (external or internal) are mere representations can be read as the 
claim that the way in which objects (spatial or mental) figure in experience (namely, spatially and temporally) does not correspond to the way these objects are when considered in abstraction from the conditions for them to figure in experience.

\section{Reconsideration of the Phenomenalist Passages}

For Kant, to claim that objects are, from the transcendental point of view, representations is just to claim that the way these objects figure in our experience provides no knowledge concerning the way they are in themselves (i.e., abstraction made of the conditions for them to figure in experience). Can this interpretation account for the passages that motivate a phenomenalist reading of transcendental idealism?

The main textual support for the phenomenalist reading comes from passages in which Kant claims that the objects of experience are appearances or representations that only exist in us or that cannot exist outside our thoughts or mind (see, for instance, KrV, A43/B59, A490-1/B518-9 and A492/B520). According to the suggestion above, all these passages should be read as making claims on the transcendental level. The claim that external objects, qua representations, have no existence outside us, outside our thoughts or outside our minds should be read as claiming that, from a transcendental point of view, these objects exist only as determinations in the mind of the transcendental subject. That, however, is not the same as claiming that these objects do actually exist in a mind, for the description of the transcendental subject does not show that such a being exist but merely draws the limits of possible experience. These passages should, therefore, be read as claiming that the way in which appearances figure in experience provides no insight into the way things are in themselves (abstraction made of the conditions for them to figure in experience).

Kant also claims that appearances, as representations, are real only in perception:

[A]ppearances, as mere representations, are real only in perception, which in fact is nothing but the reality of an empirical representation, i.e. appearance. To call an appearance a real thing prior to perception means either that in the continuation of experience we must encounter such a perception, or it has no meaning at all. [...] [For appearances are] mere representations, which if they are not given in us (in perception) are encountered nowhere at all (A493-4/B521-2).

If we restrict ourselves to the transcendental level, then perception can only be understood as the production of representations in the mind of the transcendental subject. If that is what Kant has in mind in this passage (and that seems to be the case given the claim that for a representation to be given in perception is for it to be given in us), then it is not different from the passages just discussed. At the 
empirical level, however, we need not think of the perception of a spatial object (i.e., an external appearance) as the production of a mental image (i.e., an internal appearance) in the empirical subject. We can claim that, for an empirical subject, to perceive a spatial object is just to be in a particular relation with that object, namely the relation expressed by "object $O$ figures in the experience of subject $S$ ". If that is the case, to claim that appearances exist only to the extent that they belong to possible experience (or possible perception) is just to point to the fact that the limits of empirical reality (which is composed of appearances and to which our knowledge is limited) coincide with the limits of possible experience.

Finally, we must consider the claims Kant makes in his discussion of the fourth paralogism. This is the locus classicus of the phenomenalist reading because it seems that in this section Kant tries to argue against the Cartesian skeptic by conceding that we only have immediate access to the contents of our mind but holding that empirical objects are nothing but contents of our minds - an essentially Berkelian strategy:

I am no more necessitated to draw inferences in respect of the reality of external objects than I am in regard to the reality of the objects of my inner sense (my thoughts), for in both cases they are nothing but representations, the immediate perception (consciousness) of which is at the same time a sufficient proof of their reality $(\mathrm{A} 371)$.

[...] external things - namely, matter in all its forms and alterations - are nothing but mere representations, i.e., representations in us, of whose reality we are immediately conscious (A371-2).

Kant's point is that the transcendental idealist can hold that the reality of external objects need not be inferred from the existence of certain mental states because external objects are representations whose reality is proved by immediate perception. If we think in the perception of an object as the production of a mental representation, then the phenomenalist reading of this passage is inevitable. But notice that Kant claims that the reality of any representation is proved by immediate perception. This means that the reality of internal appearances is likewise proved by perception. If we take perception to be a matter of producing mental representations, the perception (or consciousness) of mental states would require the production of another mental state - and we would face an infinite regress. At the empirical level, to say that a person perceives or is aware of a spatial object is just to say that the object figures in the person's experience. It is in this sense of "perception" that the immediate perception of a spatial object proves its existence. And that is how we should understand the claim that we can be immediately aware of the existence of spatial objects because they are representations - that is just to say that because 
they conform to the conditions of experience they can figure in our experience.

However, if one was hoping to find a refutation of Cartesian skepticism in Kant's discussion of the fourth paralogism, one will be disappointed with this antiphenomenalist reading. The possibility of a skeptic argument to the effect that we are never in contact with spatial objects is still open. This argument would aim at showing that we never perceive spatial objects - that is, that these objects never figure in our experience; what we have direct contact with are always mental states. But the phenomenalist reading does not do better in fending off the skeptical threat. Even though Kant claims that in order to refute the skeptic it is enough to show that external perception immediately proves the reality of the external object (KrV, A3767) he takes no measures to refute the skeptic who questions the supposition that we do have external perceptions and not mere internal states posing as such perceptions. Even if external objects were a species of mental representations, in order to refute the skeptic, one would have to show that not all of our representations are of another kind. Kant actually claims that in order to refute empirical idealism (which is the same as Cartesian skepticism) it is enough to point to the fact that without external perceptions not even dreams and fictions are possible ( $\mathrm{rV}, \mathrm{A377})$, but that it not a corollary of the phenomenalist reading but a very strong thesis that requires an independent argument (which Kant latter provided in his Refutation of Idealism). The anti-phenomenalist reading advocated in this paper is, therefore, perfectly compatible with Kant's argumentation in his discussion of the fourth paralogism.

\section{Conclusion}

Although Kant's claims in the Prolegomena fail to fend off the accusation of phenomenalism, I argued, in section 3, that, given the distinction between a transcendental and an empirical sense of "outside us" and "in us", Kant cannot be committed to the thesis that spatial objects are mere mental entities. In section $4 \mathrm{I}$ offer an alternative interpretation of the claim that spatial objects are mere representations and in section $5 \mathrm{I}$ argued that this interpretation can account for passages that seem to support the phenomenalist reading.

We are now in a position to understand Kant's insistence that his transcendental idealism is different from Berkeley's idealism and that the latter is an expression of skepticism. On the one hand, to characterize spatial objects as mere mental entities in the transcendental sense is to fall prey to the transcendental illusion by means of which we (empirical subjects) identify ourselves with the transcendental subject. On the other hand, one can characterize spatial objects as mere mental entities in the empirical sense only if one holds the skeptical thesis that we never 
have genuine external perceptions and, therefore, commits oneself to a form of illusionism according to which that which we assume are spatial objects figuring in our experience are always mere internal appearances.

\section{References}

Allais, L. (2015). Manifest Reality - Kant's Idealism and his Realism. New York: Oxford University Press.

Allison, H. (1973). Kant's Critique of Berkeley. Journal of the History of Philosophy, 11(1), pp.43-63.

(2004). Kant's Transcendental Idealism. An Interpretation and Defense. New Haven: Yale University Press.

Beiser, F. (2002). German Idealism: The Struggle against Subjectivism. Cambridge: Harvard University Press.

Caranti, L. (2007). Kant and the scandal of philosophy: the Kantian critique of Cartesian skepticism. Toronto: University of Toronto Press.

Guyer, P. (1987). Kant and the Claims of Knowledge. New York: Cambridge University Press.

Kant, I. (1998). Critique of Pure Reason. Translated by Paul Guyer and Allen Wood. Cambridge: Cambridge University Press.

. (2004). Prolegomena to Any Future Metaphysics. Translated by Gary Hatfield. New York: Cambridge University Press.

Strawson, P. (1966). The Bounds of Sense. New York: Routledge.

Smith, N.K. (2003 [1918]). A Commentary to Kant's 'Critique of Pure Reason'. New York: Palgrave Macmillan

Turbayne, C. (1955). Kant's Refutation of Dogmatic Idealism. Philosophical Quarterly, 5, pp. 225-44.

Van Cleve, J. (1999). Problems from Kant. Oxford: Oxford University Press. 